\title{
Cleanest City of India in Swachh Bharath Mission (2015-16): Mysore Model and the Lessons for other Cities
}

\author{
Manjunatha SN, Bhavani Nivetha M*
}

\section{Manjunatha SN, Bhavani Nivetha $\mathrm{M}^{*}$}

Department of Community Medicine, Mysore Medical College and Research institute, Mysore-570001, Karnataka, INDIA.

\section{Correspondence}

\section{Dr. M. Bhavani Nivetha}

Postgraduate Student, Department of Community Medicine, Mysore Medical College and Research institute, Mysore-570001, Karnataka, INDIA. Phone no: +919940572924

Email: bhavani.nivetha@gmail.com

\section{History}

- Submission Date: 22-11-2018;

- Revised Date: 15-01-2019;

- Accepted Date: 15-03-2019.

DOI : 10.5530/ijmedph.2019.1.2

Article Available online

http://www.ijmedph.org/v9/i1

\section{Copyright}

(C) 2019 Phcog.Net. This is an openaccess article distributed under the terms of the Creative Commons Attribution 4.0 International license.

\begin{abstract}
Background: Mysore was ranked as the cleanest city for the second successive time in 2016. Total sanitation is the goal of Swachh Bharath Mission and good practices and models need to be shared and adopted. In this context an explorative research was conducted to prepare the list of key drivers for sanitation in Mysore. Methods: The sanitation value chain for Mysore city was constructed. It consisted of containment, emptying, transport, treatment and disposal. The key stake holders in this chain were interviewed and field visits were done for status and process assessment. Stake holders in this chain were grouped for common roles and strength, weakness, opportunity and threat analysis was done. Individual interviews and focus group discussions were conducted. Results: In Mysore we have found that only $10 \%$ of the households depend on onsite facilities for faecal sludge management and $88 \%$ of the household have direct sewer connections. Only $12 \%$ of the sewage is left untreated into receiving waters or the natural environment. Door to door collection of solid waste is present in all the corporation wards. Open air defecation is far and few and restricted to couple of slums and construction sites. Bylaw framing, planning, implementation of solid waste management by the municipal corporation is satisfactory. Conclusion: The city of Mysore had a good history and basic infrastructure since a long time. The Swachh bharath mission played a catalytic role in the acceleration of sanitation process. Involvement of voluntary organizations, good leadership at municipal corporation level made this success possible.
\end{abstract}

Key words: Swachh Bharath, Key sanitation drivers, Sanitation value chain, Faecal sludge management, Solid waste management.

\section{INTRODUCTION}

Sanitation generally refers to the provision of facilities and services for the safe disposal of human urine and faeces. Inadequate sanitation is a major cause of disease world-wide and improving sanitation is known to have a significant beneficial impact on health both in households and across communities. The word 'sanitation' also refers to the maintenance of hygienic conditions, through services such as garbage collection and wastewater disposal. ${ }^{1}$ In 2015, only $39 \%$ of the global population (2.9 billion people) used a safely managed sanitation service - defined as use of a toilet or improved latrine, not shared with other households, with a system in place to ensure that excreta are treated or disposed of safely. Poor sanitation is linked to transmission of diseases such as cholera, diarrhoea, dysentery, hepatitis A, typhoid and polio. ${ }^{2}$ Only 31 per cent of India's population use improved sanitation, in rural India only 21 per cent use improved sanitation facilities. ${ }^{3}$ About $53.1 \%$ of the households do not have a toilet and $38 \%$ of urban households in India use septic tanks as onsite sanitation facilities. ${ }^{4}$ Half of the Indian population (52\%) is still defecating in the open. ${ }^{5}$ In order to improve the sanitation in India the government of India launched its ambitious programme "Swachh Bharat Mission"(SBM) in 2014 with the following objectives

- Elimination of open defecation;

- Eradication of Manual Scavenging;

- Modern and Scientific Municipal Solid Waste Management;

- To effect behavioral change regarding healthy sanitation practices;

- Generate awareness about sanitation and its linkage with public health;

- Capacity Augmentation for ULBs to create an enabling environment for private sector participation. ${ }^{6}$

Mysore is the second largest city in Karnataka and plans for organized development of the city exist as far back as $1904 .{ }^{7}$ Karnataka is also one of the states in the country to have state sanitation strategy. So, when swach bharat abhiyaan mission conducted a survey, Mysore was declared as the cleanest city in the country for two consecutive years $\left(2015\right.$ - 2016) ${ }^{8,9}$ It is important to analyse how Mysore managed to achieve this feat, so that even other cities in the country can emulate the model Mysore follows. This will help the
Cite this article : Manjunatha SN, Nivetha BM. Cleanest City of India in Swachh Bharath Mission (2015-16): Mysore Model and the Lessons for other Cities. Int J Med Public Health. 2019;9(1):4-7. 
country to achieve and sustain the mission's objective in future. Sustainable sanitation is possible only by thorough understanding of the sanitation. The sanitation value chain is the collection of units and processes involved in the management of human waste, starting with the user interface (e.g., the toilet), collection, transport, treatment and ending with the reuse of the material resources (e.g., water, nutrients, energy, organic matter); this reuse may be indirect (After the material is returned to the environment) or it may be direct. It identifies the main components that need to be addressed in order to provide safe and sustainable Water, Sanitation and Hygiene (WASH) services for communities. They include ensuring the availability and storage of water, the design and construction of toilets for specific target groups and creating systems of disposal and treatment for solid and liquid waste. ${ }^{10}$ In order to get an understanding about the sanitation situation in Mysore, in this study we constructed the sanitation value chain for liquid waste disposal in Mysore.

\section{MATERIALS AND METHODS}

\section{Objectives}

1. To conduct a SWOT analysis of sanitation situation at Mysore.

2. To identify the key drivers for the success in Sanitation.

3. To identify the lessons for other cities to emulate.

\section{Methodology}

Study period: October 2016-June 2017.

Study setting Mysore city coming under the Jurisdiction of Mysore city corporation.

Study design: Mixed method (Quantitative and Qualitative).

Data collection: This was a mixed method study where both qualitative and quantitative data was collected. For qualitative data group discussion was done using nominal group technique/ Quantitative data was collected using semi-structured questionnaire on the stake holders and record review was done.

Sample size: 19 for in-depth interviews and 6 for group discussion (2 were conducted).

\section{Data Capture Methods}

1. Field visits: visited Waste collection points and Sewage treatment plant with checklists.

2. Group discussions with key stake holders including waste handlers, corporation officials, people's representatives (corporators) and general public.

3.In depth Interviews with selected key stake holders.

4. Review of data sources maintained at treatment plants and corporation offices.

\section{Data Analysis}

Saturation was reached within 15-20 people. Interview and discussion data was transcribed and analyzed using ethonograph software version 6.7. Triangulation was done between quantitative and qualitative data.

\section{RESULTS}

\begin{tabular}{|c|c|}
\hline Strengths & Weakness \\
\hline $\begin{array}{l}\text { - Manual scavenging is eradi- } \\
\text { cated } \\
\text { Historical advantages of un- } \\
\text { derground drainage systems } \\
\text { and good city planning } \\
\text { - Very less slum population } \\
\text { - City of palaces which is a } \\
\text { tourist attraction with world } \\
\text { famous Dasara festival. } \\
\text { - Political will is very strong } \\
\text { People are very committed } \\
\text { in maintaining the city clean } \\
\text { causing excellent commu- } \\
\text { nity participation }\end{array}$ & $\begin{array}{l}\text { - Poor inter-sectoral coordi- } \\
\text { nation } \\
\text { - Sewage treatment plant still } \\
\text { besides residential area } \\
\text { - New Land filling area is yet } \\
\text { to be commissioned. } \\
\text { - Enforcement of law is not } \\
\text { very strong }\end{array}$ \\
\hline Opportunities & Threats \\
\hline $\begin{array}{l}\text { - Since cultural capital of } \\
\text { Karnataka lot of importance is } \\
\text { given by the policy makers } \\
\text { Many NGOs are working in } \\
\text { the cleanliness drive with good } \\
\text { track record } \\
\text { More than } 80 \% \text { of population is } \\
\text { literate } \\
\text { Corporate Social Responsibility } \\
\text { from companies like Infosys and } \\
\text { other private sectors. }\end{array}$ & $\begin{array}{l}\text { Possibility of water scarcity in } \\
\text { case of monsoon failure can } \\
\text { affect the sanitation situation. } \\
\text { Rapid growth of population } \\
\text { causes added burden for } \\
\text { existing resources } \\
\text { New industries entering into } \\
\text { City hindering the cultural } \\
\text { status. }\end{array}$ \\
\hline
\end{tabular}

\section{Table 2: Solid Waste Management in Mysore.}

Solid waste management in Mysore

- Coloured bins (Red and blue) are distributed to citizens for segregation of dry and wet waste at source.

- Door to Door collection is done in all 65 wards

- Vehicles transporting waste are monitored using GPS

- Outsourcing of waste collection is done in some wards to private sector

- 4 Zero Waste Management plants are set up in different parts of the city to treat solid waste

- Vegetable waste is sent to Pinjrapole society for feeding stray cattles

- Vermicomposting is done at Chamaraja Zoo Gardens

- Eco friendly vessel washing powder and toilet floor cleaning powder is prepared from citrous fruit wastes and others

- Organic manure is produced from waste and is sold at subsidized cost.

- Banning of plastic carry bags is in effect in entire city

- Mobile app for informing corporation authorities regarding violations

- On line grievance addressal for the public

\begin{tabular}{|c|c|c|c|c|c|}
\hline $\begin{array}{c}\text { Total amount } \\
\text { of solid waste } \\
\text { generated per day } \\
\text { (in tonnes) }\end{array}$ & $\begin{array}{l}\text { Total amount of } \\
\text { municipal solid } \\
\text { waste collected per } \\
\text { day (in tonnes) }\end{array}$ & $\begin{array}{c}\text { Number of public } \\
\text { dustbins }\end{array}$ & $\begin{array}{l}\text { Number of vehicles } \\
\text { for transportation } \\
\text { and disposal }\end{array}$ & $\begin{array}{l}\text { Area of land fill site } \\
\text { (in } \mathrm{Km} \text { ) }\end{array}$ & $\begin{array}{l}\text { Percentage of } \\
\text { household covered } \\
\text { by door-to-door } \\
\text { collection }\end{array}$ \\
\hline 240 & 240 & 2871 & 52 & $\begin{array}{c}\text { Yet to be } \\
\text { commissioned }\end{array}$ & 30 \\
\hline
\end{tabular}




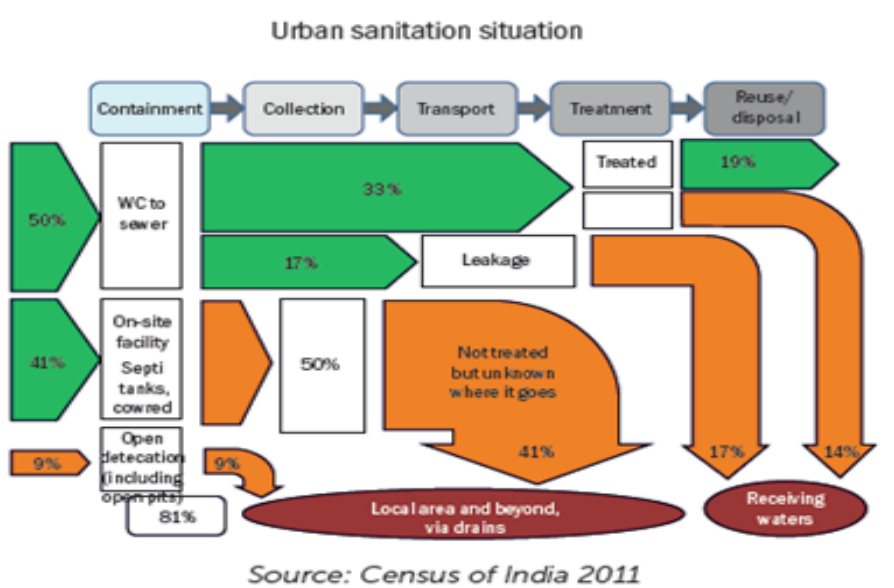

Figure 1: Sanitation Value Chain of Urban India.

FIGURE 2. FECAL FLOW DIAGRAM FOR MYSORE KARNATAKA

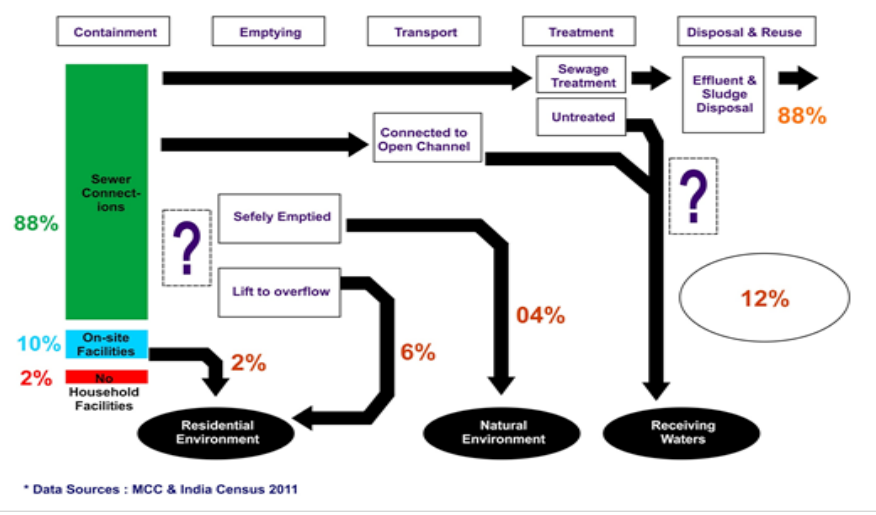

Figure 2: Sanitation Value Chain of Mysore City.

\section{DISCUSSION}

In Mysore we have found that only $10 \%$ of the households depend on onsite facilities for faecal sludge management and $88 \%$ of the household have direct sewer connections. Only $12 \%$ of the sewage is left untreated into receiving waters or the natural environment (Figure 2). Other cities like trichy which also made to top 5 cleanest cities had $60 \%$ of the city with sewer connections, ${ }^{12}$ other city Chandigarh also had $95 \%$ of the population catered to by sewer connections. ${ }^{13}$ On the other hand according to census 2011, about 45 per cent of urban Indian households depend on on-site facilities for faecal collection and containment (Figure 1). The Performance Assessment System (PAS) project conducted by the CEPT University also showed similar results, Under this project, the service level benchmark data submitted to Government of India by 16 states covering 1564 cities reveal that 1190 cities are completely dependent on On-site sanitation (76\%), 369 (24\%) cities use a mixed system with both sewer network and on-site systems and there are only 5 cities with full sewer systems. ${ }^{14}$ All these results point out that a well-established sewer connections in Mysore is one of the important driver for the clean city status. Although sewer connections form important part of the Sanitation Value chain it is responsible only for collection and containment, proper treatment and disposal should be coupled with that inorder to maintain good sanitation. In our study the data shows that $88 \%$ of the faecal waste is safely treated and disposed. Mysore is adequately equipped with sewage treatment plants with present sewerage capacity of 157.65 MLD which was designed as per the requirements of the city in the year $2011 .^{7}$
Other cities which fared better in swachatha survey like trichy with 59\% sewer connections showed that $60 \%$ of the faecal waste was safely disposed, Delhi with $68 \%$ sewer connections showed that $56 \%$ of faecal waste was disposed of safely. So, the cities with sewer connections show better treatment and disposal of waste which was also the case in Mysore. Centre for Science and Environment (CSE) set out to follow the trail of human excreta in 11 cities across India, which showed alarmingly poor results in Srikakulam, Solapur and Dewas where only 0\%, 2\% and 7\% of faecal waste was safely disposed had more than $50 \%$ dependence on onsite facilities. ${ }^{12}$ In another extensive desk review to capture the status of Faecal Sludge Management in six states namely Delhi, Gujarat, Madhya Pradesh, Maharashtra, Uttar Pradesh and Tamil Nadu it was again concluded that adequate facilities and services for collection, transportation, treatment and disposal of urban domestic septage (Faecal waste from septic tanks) do not exist in Indian cities. Most On-Site Sanitation Systems (OSS) are emptied manually in the absence of suitable facilities. ${ }^{15}$ The Figure 2 depicts the faecal flow of the nation in the urban area which shows that most of the faecal sludge ends up in the environment and only $19 \%$ of faecal matter is safely disposed and $0 \%$ from onsite system is managed properly. Another Review of Fecal Sludge Management in 12 Cities was undertaken to analyze fecal sludge management in a variety of cities from Latin America, Africa, South Asia and East Asia which showed that Almost two-thirds of households in the cities studied rely on on-site sanitation facilities, On average, fecal waste from only 22 percent of households using on-site systems is safely managed, In only two of the 12 cities studied was fecal waste from more than 50 percent of households using on-site systems safely managed. The city which was chosen from South Asia was Delhi, it was shown that $0 \%$ of waste from on-site system were managed properly. ${ }^{16}$ All the above results points out that underground sewer connections are inturn leading to safe disposal of faecal sludge as it is almost always connected with proper disposal and treatment system. The reason for this maybe because maintenance of onsite facilities lies with the owner and there is no binding rule for regular desludging and cleaning. Many other factors like non-availability of mechanical instruments, cost can also play a role. So, from our data it is clear that the sanitation value chain system functioning in Mysuru is wholesome, the reason mainly can be attributed to underground sewer connections coupled with well-functioning safe disposal facilities. The swacha bharat mission was launched in 2014, but the main objective of the mission was on only a part of sanitation value chain like Containment and collection. Though it is mentioned in the mission guidelines that construction of latrine should be coupled with sewer connection and proper disposal or in the absence of sewer connection an on-site sanitation facility with provision for proper treatment and desludging, the reality is not so. ${ }^{6}$ Almost half the Indian household depends on the on-site facilities for faecal disposal but we are still not equipped with necessary facilities to properly treat and dispose/reuse the faecal sludge. The mapping of faecal flow in every city will help us to find the bottle necks encountered across the faecal management chain. It has been proposed in $\operatorname{SBM}(\mathrm{U})$ that all the cities should come up with city sanitation strategy, the formulation of such sanitation value chains across various cities will serve as the starting point in designing these strategies. The strengths identified for successful sanitation system in mysore included eradication of manual scavenging (Table 1). Despite progress, manual scavenging persists in India. According to the India Census 2011, there are more than 2.6 million dry latrines in the country. Since Mysore is $88 \%$ dependant on underground Sewer connections with only $5 \%$ of slum population the manual scavenging was easy to eradicate as only onsite facilities require manual cleaning. ${ }^{7}$ Another strength is the political will and community participation which were the key drivers for success in Mysore. Maharashtra took the top rank hosting 6 cities that score in the top 20 mainly because of the extraordinary political will showed by 
the state, State level initiatives were successfully reflected at city level in the form of innovative ideas and effective implementation to achieve the status of Open Defeacation Free state. ${ }^{17}$ The importance to Mysore city given by policy makers is of paramount importance which was identified as an area of opportunity, other major cities like Delhi, Navi Mumbai, Vishakapatnam, Chandigarh which constantly features in the clean city list also reflect the same situation. ${ }^{5,8}$ Another area that has to be taken advantage of in Mysore is Corporate Social Responsibility (CSR) by companies and Non-governmental organization involvement (Table 1). In a study facilitated by Indian sanitation coalition analyses was done on CSR efforts in WASH by the 100 companies, it was reported that $90 \%$ of the 100 companies reported at least one CSR intervention in WASH over the last three years, it also indicated that one of the most popular states for CSR in WASH was Karnataka with 13 companies working for sanitation. ${ }^{18}$ Many national and international NGO's like Centre for science and environment, Wateraid have been working with good track record assisting the government in research activities, coming up with sanitation plans for cities and sludge management workshops for stakeholders. New landfill site is still under consideration in Mysore which is one of the weakness, According to CPCB, 2013 report, till date, India has 59 constructed landfill sites and 376 are under planning and implementation stage. Apart from this, 1305 sites have been identified for future use. Clearly the landfill sites across the nation are inadequate and Mysore which is leading the country in many sanitation parameters is also suffering the same fate. Poor-intersectoral coordination is another weakness, Sanitation is a complex topic, with links to health and to social and economic development. It affects many but is championed by few, full involvement of the health sector in sanitation is crucial along with all other concerned departments and agencies to achieve better sanitation.

With regard to solid waste management Mysore has taken various innovative approaches (Table 2). No city in India can claim 100\% segregation of waste at dwelling unit, Mysore is striving to achieve this by provision of free bins to households. Even a city like Mysore was able to achieve only $30 \%$ door to door collection of waste, on an average according to national data only $70 \%$ waste collection is observed, while the remaining $30 \%$ is again mixed up and lost in the urban environment (Table 3). ${ }^{19}$ This was an important gap identified, the performance in Mysore was very low compared to national status. In contrast to above finding, Alappuzha is among five places in the world that have been recognised by the United Nations Environment Programme (UNEP) as success stories in fighting the problem of solid waste. ${ }^{20}$ The city has come up with a decentralized approach to solid waste management which can be replicated in other cities, a city like Mysore can certainly try to adopt such an approach which will help to retain its clean city status.

\section{CONCLUSION}

The construction of sanitation value chain of Mysore has helped us to trace the faecal flow in the city. The faecal sludge management of Mysore is excellent with $88 \%$ of waste being properly disposed. The main driver identified for this is the well-established sewer connections around the city. The Sanitation situation is good in Mysore but certain areas identified in SWOT analysis like the threats of population explosion and urbanization and weakness of poor solid waste management has to be addressed if Mysore wishes to retain its clean city status in future.

\section{Limitation}

The study was done by reaching as many stake holders possible, but there are chances of missing information. The study utilized many secondary data so there are chances of information bias.

\section{CONFLICT OF INTEREST}

The auhtors declare that there is no conflict of interest.

\section{ABBREVIATIONS}

SBM: Swachh Bharat Mission; ULB: Urban local bodies; WASH: Water, Sanitation and Hygiene; PAS: Performance assessment system; CEPT: Centre for Environmental Planning and Technology; OSS: On-site sanitation systems; CSE: Centre for science and environment.

\section{REFERENCES}

1. Sanitation. World Health Organization. 2015 [cited 12 July 2018]. Available from: http://www.who.int/topics/sanitation/en/

2. Sanitation fact-sheets. World Health Organization. 2015 [cited 12 July 2018] Available from: http://www.who.int/news-room/fact-sheets/detail/sanitation

3. Water, Environment and Sanitation I UNICEF. Unicef.in. 2008 [cited 12 July 2018]. Available from: http://unicef.in/Story/1125/Water--Environment-and-Sanitation

4. Census of India Website: Office of the Registrar General and Census Commissioner, India. Censusindia.gov.in. 2011 [cited 12 July 2018]. Available from:http:// censusindia.gov.in/2011census/hlo/hlo_highlights.html

5. Swachhta status report. New Delhi: National Sample survey Office; 2016 [cited 12 July 2018]. Available from: http://mospi.nic.in/sites/default/files/publication_ reports/Swachhta_Status_Report\%202016_17apr17.pdf

6. Guideline for Swachh Bharat Mission - Urban. Delhi: Ministry of Housing and Urban Affairs. 2017;9-10

7. City Sanitation Plan, Mysore. Mysore: administrative staff college of India. 2011 [cited 18 July 2018]. Available from: http://www.municipaladmn.gov.in/sites/ municipaladmn.gov.in/files/CSP_Mysore.pdf

8. Ministry of housing and Urban affairs. Swachh Bharat ranking of cities [Internet] 2015. Available from: http://pib.nic.in/newsite/PrintRelease.aspx?relid=124639

9. Pandey N. Swachh Survekshan 2016: Mysuru cleanest city of India. The Hindu: Business Line. 2016 [cited 18 July 2018]; Available from: https://www.thehindubusinessline.com/news/swachh-survekshan-2016-mysuru-cleanest-city-ofindia/article8240565.ece

10. Technology Options for the Sanitation Value Chain, $1^{\text {st }}$ ed. Bengaluru; 2016;1-3. [cited 18 July 2018]. Available from: http://file:///C:/Users/bhavani\%20nivetha/ Desktop/SRM\%20conference/CSTEP_Technology_Options_for_the_Sanitation_Value_Chain_Report_2016.pdf

11. CSR in Wash: What India's top companies are upto?. Mumbai: Samhita social ventures. 9-16. Available from: http://ficci.in/spdocument/20736/CSR-in-WASH. pdf

12. Sanitation's agenda: water-toilet-waste-pollution nexus. Swachhbharaturban gov.in. 2015 [cited 30 July 2018]. Available from: http://swachhbharaturban.gov. in/writereaddata/Day\% 201-Session \% 201-All\%20PPTs.pdf

13. Chandigarh.gov.in. [cited 30 July 2018]. Available from: http://chandigarh.gov.in/ cmp2031/physical-infra.pdf

14. Sarkar SK, Bharat GK. Discussion Paper on Faecal Sludge Management in Urban India: Policies, Practices and Possibilities. Teriin.org. 2016. Cited on 30 July 2018. Available from: http://www.teriin.org/policy-brief/discussion-paper-faecalsludge-management-urban-india-policies-practices-and

15. An assessment of faecal sludge management policies and programmes at national and state level. New Delhi: Water Aid. 2016;22-9. [cited 30 July 2018] Available from: http://wateraidindia.in/wp-content/uploads/2016/01/FaecalSludge-Management-Report.pdf

16. Blackett IC, Hawkins PM, Heymans C. The missing link in sanitation service delivery: A review of fecal sludge management in 12 cities. Water and sanitation program research brief. 2014. Available from: http://documents.worldbank. org/curated/en/395181468323975012/The-missing-link-in-sanitation-servicedelivery-a-review-of-fecal-sludge-management-in-12-citie

17. Journey of ODF Maharashtra. Pas.org.in. 2017 [cited 30 July 2018]. Available from: http://www.pas.org.in/Portal/document/UrbanSanitation/uploads/Journey\%20of\%200DF\%20Maharashtra.pdf

18. CSR in Water, Sanitation and hygiene. Ficci.in. [cited 30 July 2018]. Available from: http://ficci.in/spdocument/20736/CSR-in-WASH.pdf

19. Joshi R, Ahmed S. Status and challenges of municipal solid waste management in India: A review. Cogent Environmental Science. 2016;2(1).

20. The Hindu. Alappuzha leads by example]. 2017 [cited 30 July 2018]. Available from: https://www.thehindu.com/news/national/kerala/alappuzha-leads-by-example/article21039412.ece\# 